\title{
Anonymity, Reciprocity, and Conformity: Evidence from Voluntary Contributions to a National Park in Costa Rica
}

\author{
Francisco Alpizar ${ }^{\mathrm{a}}$ \\ Fredrik Carlsson ${ }^{\mathrm{b}}$ \\ Olof Johansson-Stenman ${ }^{\mathrm{c}}$ \\ Working Papers in Economics no. 245 \\ February 2007 \\ Department of Economics \\ Göteborg University
}

\begin{abstract}
We investigate the role of anonymity, reciprocity, and conformity for voluntary contributions, based on a natural field experiment conducted at a national park in Costa Rica. Contributions made in public in front of the solicitor are $25 \%$ higher than contributions made in private. Giving subjects a small gift before requesting a contribution increases the likelihood of a positive contribution. At the same time, the conditional contribution decreases. The total effect of giving a gift is positive but small, and taking the cost of the gift into account, it is far from profitable. When the subjects are told that the typical contribution of others is $\$ 2$ (a small contribution), the probability of a contribution increases and the conditional contribution decreases, compared with providing no reference information. Providing a high reference level $(\$ 10)$ increases the conditional contributions. Overall, the total effects have the expected signs, although the magnitudes are smaller than what one might have expected based on existing evidence from laboratory experiments.
\end{abstract}

JEL-classification: C93, Q50

Key words: Voluntary contributions, anonymity, reciprocity, conformity, natural field experiment.

Acknowledgments: Financial support from the Swedish Research Council and from Sida to the Environmental Economics Unit at Göteborg University and to the Environment for Development Center at CATIE is gratefully acknowledged. Our gratitude goes to the park authorities at Poas National Park and its Conservation Area (ACCVC). We thank Martin Kocher, Rupert Sausgruber, participants at the ESA 2006 conference and at the 2006 Nordic Workshop on Behavioral Economics, as well as seminar participants at Göteborg University, Resources for the Future, Stockholm University, and Växjö University for many valuable comments.

${ }^{a}$ Environment for Development Center, Tropical Agricultural and Higher Education Center (CATIE), 7170, Turrialba, Costa Rica. Tel: + 506558 2215, e-mail: falpizar@catie.ac.cr

${ }^{\mathrm{b}}$ Department of Economics, Göteborg University, Box 640, SE-40530 Göteborg, Sweden. Tel: + 4631 7734174, e-mail: Fredrik.Carlsson@economics.gu.se

${ }^{\mathrm{c}}$ Department of Economics, Göteborg University, Box 640, SE-40530 Göteborg, Sweden. Tel: + 4631

7732538, e-mail: olof.johansson@economics.gu.se 


\section{Introduction}

Although a large part of economic theory assumes a narrow definition of selfishness, much evidence suggests that people are often not motivated solely by material payoffs. Besides straightforward observations of charity (see Andreoni, 2004 and Vesterlund, 2006 for excellent overviews), there is an overwhelming amount of recent experimental evidence (see for example Ledyard, 1995 and Camerer, 2003). Moreover, unlike the atomistic and amoral Homo Economicus, people often do not act independently of private and social norms. Most of us consider it important to be regarded positively by others (Brennan and Pettit, 2004; Kuran, 1995), but we also seem to prefer to have a positive view of ourselves independent of the view of others (Akerlof and Kranton, 2000; Benabou and Tirole, 2002, 2006). As expressed by Adam Smith (1759): "The most sincere praise can give little pleasure when it cannot be considered as some sort of proof of praise-worthiness." However, clear empirical evidence outside the lab of what influences altruistic or charitable behavior is still scarce. Using the terminology of Harrison and List (2004), this paper presents the results of a natural field experiment in Costa Rica, where the importance of anonymity, reciprocity, and conformity for people's voluntary contributions to a national park are investigated.

Laboratory experiments have many advantages, in particular with respect to the possibility of holding other possible influences than the one under investigation fixed. Levitt and List (2006) argue that lab experiments therefore are useful in generating qualitative insights. Obviously, laboratory experiments also have drawbacks. Levitt and List (2006) argue that one needs to be very careful when generalizing quantitative findings outside the lab environment. They conclude that laboratory experiments and data generated in the field are complements rather than substitutes. We concur with this view.

In broad terms, several potential reasons for non-selfish behavior have been identified in the experimental literature, including the following: (i) People prefer to conform to what others do. Thus, people behave more unselfishly if they observe that others act unselfishly. (ii) People reciprocate; that is, if others have been nice to you, you tend to be nice to them. (iii) People are motivated both by their own view of

themselves as well as by how other people view them. This implies that people tend to act less altruistically if no one observes their actions. 
The purpose of this paper is to test the absolute as well as the relative importance of these three reasons for non-selfish behavior. This is done by conducting a natural field experiment on voluntary contributions to a national park in Costa Rica, were international tourists were asked if they would like to contribute to the park. The effect of anonymity is tested by letting the subjects contribute their money either openly in the presence of the solicitor, or in a sealed envelope. The effect of reciprocity is investigated by handing over a small gift (a refrigerator magnet) to a sub-sample of subjects, prior to their contribution decision. With reciprocity we mean that people are reciprocal if they reward kind actions and punish unkind actions towards them; cf. Falk and Fischbacher (2006) and Rabin (1993). In principle, the kindness of the action can be evaluated both in terms of the consequences and in terms of intentions (Dufwenberg and Kirchsteiger, 2004; Rabin, 1993); simply put, kind actions appreciated for their good consequences can trigger punishing behavior if the intentions are regarded as bad. We investigate the effect of conformity by providing the subjects with information about the contributions of previous subjects. The information is varied among subjects and we include the case of providing no information as well. By conformity we mean that people care about their own contribution relative to the contributions of others; see Bernheim (1994) for an example of a model of conformity where people care about their status in terms of their relative contribution to a public good.

An attractive feature of our design is that it allows us to separate reciprocity from conformity, which is not possible in most studies of conditional cooperation. For example, if people contribute more when others contribute more in public good games, this may in part reflect reciprocity and in part conformity. Another attractive feature is that we are able to separately analyze the effects on the probability that a person contributes and on the magnitude of the contribution conditional on a positive contribution.

Just looking at the raw data, our findings can be summarized as follows: Anonymity decreases contributions by about 25\%. Giving a small gift (reciprocity) increases contributions by about 5\%. However, this effect is not at all sufficient to cover the cost of the gift given to the subjects. A reference level of $\$ 10$ increases contributions by about $4 \%$ compared with not providing any reference contribution information. However, providing a lower reference level of $\$ 2$ decreases contributions by $23 \%$ 
compared to the baseline of no reference level. The effects of anonymity, reciprocity, and providing social reference points are similar in a regression analysis. There are also some interesting asymmetric effects on the probability of contributing anything at all and on the contribution conditional on a positive contribution: In the reciprocity treatment more people contribute, while the average conditional contribution is lower. Increasing the reference level decreases the probability of a positive contribution, but increases the conditional contribution.

The reminder of this paper is organized as follow: Section 2 provides a brief literature review of earlier studies with an emphasis on field experiments, Section 3 presents our field-experimental design, Section 4 the corresponding results, and Section 5 concludes the paper.

\section{Previous studies}

There are several public good laboratory experiments that look at the role of anonymity; see e.g. Laury et al. (1995), Masclet et al. (2003), and Rege and Telle (2004). For example, Rege and Telle (2004) considered a standard public good game with ten subjects in each group. In one sub-sample the subjects had to reveal their contribution to the whole group after making the contribution decision. The average contribution almost doubled with public observability. Of more relevance to this study is List et al. (2004), who analyzed charitable contributions to a Center for Environmental Policy Analysis at the University of Central Florida. They used three different information treatments: (i) completely anonymous responses, (ii) the experimenter knows the response, and (iii) the whole group knows the response. The largest share of yes responses was obtained when the whole group was informed of the response, followed by the case when only the experimenter knew the response. We have only found one field experiment investigating the role of anonymity. Soetevent (2005) investigated the role of anonymity in Dutch churches, using closed and open collection bags. The use of open baskets, where close neighbors in the church could identify a donor's contribution, increased overall contributions by about $10 \%$ in the second offering of the services.

There is much evidence from laboratory experiments consistent with reciprocity; see for example Fehr and Gächter (2000), Hoffman et al. (1996) and Roth (1995). 
Cialdini (2001) provides a number of real world examples from fund raising to politics where the principle of reciprocity plays an important role. Falk (2005) is the only field experiment we are aware of that studies reciprocity directly, i.e. how people respond to someone after a gift has been given to them. He found a strong and significant effect of including a gift with the donation letter; participation increased by 2 percentage points if a small gift (1 post card) was included and by 9 percentage points if a large gift (four post cards) was included. ${ }^{1}$

Many experimental results can be interpreted in terms of conditional cooperation. Some public good studies can be questioned based on unclear causality, since contributions may affect the expectation of others' contributions rather than the other way around. However, Fischbacher et al. (2001) provide clear evidence based on the strategy method: They found that about $50 \%$ of the subjects increase their contribution in a one-shot public good game if others do so as well. This is also consistent with field evidence of Andreoni and Scholz (1998), who, based on a consumer expenditure survey, found that donors respond positively to an increase in contributions by others in their reference group, which was defined in terms of socioeconomic variables. Bohnet and Zeckhauser (2004) found that informing respondents about the average offer in an ultimatum bargaining game significantly increases offers and offer-specific rejection probabilities. Potters et al. (2005) find that sequential moves in a public good game results in a larger provision of the good, because the follower mimics the action of the leader.

We are aware of four field experiments that analyze the effect of conformity or conditional cooperation. Frey and Meier (2004) analyzed the behavior of students in Zurich who had the opportunity to contribute to two social funds every semester. The contributions were higher when they were informed that many other students were contributing, although the effect was not statistically significant. Shang and Croson (2006) investigated how information about a typical contribution to a radio station affects subject contributions. They found that the highest reference amount (\$300) gives a significantly higher contribution than giving no information at all. The direction for smaller amounts (\$75 and \$180) was the same, although not statistically significant.

\footnotetext{
${ }^{1}$ The motives of the postcards were painted by kids together with the text, "Our benefits lie in children's smiles." One may imagine that they were much more effective than what most other motives would have been.
} 
Heldt (2005) found that Swedish cross-country skiers were more likely to contribute to the track maintenance if many others contributed. Martin and Randal (2005) found that visitors to a museum put more money into a transparent box, thereby donating money to the museum, when there was money in the box compared to when the box was empty.

\section{Design of field experiment}

The natural field experiment concerns contributions of visiting international tourists to the Poas National Park (PNP) in Costa Rica in 2006. Much effort was spent on ensuring that the situation was realistic and credible, and there was nothing indicating that this was a university study with the aim of analyzing people's behavior. This is potentially very important since, as noted by Levitt and List (2006), a perceived experimental situation may highlight people's sense of identity or self-image to a larger extent than outside the experimental situation; cf. Akerlof and Kranton (2000).

Our five solicitors were officially registered interviewers of the Costa Rican Tourism Board. We initially sent invitations via email inviting them to a first screening meeting where we evaluated their personalities and abilities to speak fluently in both Spanish and English. Out of ten potential solicitors interviewed, we chose five who fulfilled all our requirements. The five solicitors participated randomly in all parts of the experiment, except for one person who could not participate in the reciprocity treatments; in the regression analysis we therefore control for solicitor effects. The solicitors underwent extensive, paid training sessions both in the classroom and in the field. Once they were ready to start, we dedicated a whole week to testing their performance and to making small adjustments in the survey instrument. In addition, there were daily debriefing questions and regular meetings with the whole team to make sure that all solicitors were using the exact wording of the scenarios.

Solicitors approached international tourists after they had visited the volcano crater, which is the main attraction of the park. They were approached at a "station" decorated with the logos of the PNP, the National System of Protected Areas (SINAC), and CATIE, ${ }^{2}$ in the area outside the restaurant and souvenir shop. The solicitors wore uniforms with the logos of the PNP and CATIE plus formal identification cards that included a photo and signatures of the park authorities. The uniforms were very similar

\footnotetext{
${ }^{2}$ Spanish acronym for the Tropical Agricultural Research and Higher Education Center, which had the main responsibility for data collection.
} 
to those used by the park rangers at PNP. A formal letter authorizing the collection of contributions was also clearly visible.

Only international tourists who could speak either Spanish or English participated in the experiment. The subjects were approached randomly, with the exception that two people in the same group of visitors were never approached. The selection was one of the key elements of the training sessions, and we checked for biases in the selection of subjects daily. No corrections were required after the pilot sessions.

Initially, subjects were asked if they were willing to participate in an interview about their visit to the PNP. No mention of voluntary contributions took place at this stage, so we expect that participation was not affected by monetary considerations. Overall participation rates were very high (above 85\% each day). Once we established that they were international tourist and that they had already visited the crater, the solicitors proceeded with the interview. Before the actual experiment, subjects were asked a few questions regarding their visit to Costa Rica and to the national park. The solicitors were provided with standardized replies to the most common questions regarding the survey, the experiment, the institutions involved, etc. For further information the participants were advised to talk to the main supervisor of the contribution campaign.

The experiment involved three different treatments: (1) An examination of the role of anonymity for individual contributions, (2) an exploration of the effect of giving a small gift before asking for a contribution to the national park, and (3) a study on the effect of providing a changing social reference point on individual contributions. Each treatment required slight modifications of the interviewing script, but we were very careful in limiting the differences among the treatments. Subjects also received a card where they could read the scenario and the instructions for the voluntary contribution. The actual experiment began with the following sentence:

"I will now read to you some information about the funding of national parks in Costa Rica. Here is a paper with the information I will read." 
In the reciprocity treatment, the solicitor then gave the gift to the participant and said:

"Also, this is a little gift in appreciation of your time."

The treatments without reciprocity simply did not include any gift or the associated information. The gift was a colorful, handcrafted refrigerator magnet, depicting the main attractions of the PNP: the lagoon, the crater, and the forest. The retail value of the gift is $\$ 3$ and its cost for the park administration is approximately $\$ 1.50$. In order to avoid confusion and cross contamination between the treatments with and without gifts, they were done sequentially. After this, the participants were told about the main purpose of the request for a contribution:

"The System of National Parks in Costa Rica is now suffering from the lack of funds to achieve a good management of the parks, both for biodiversity conservation and tourism. Available funds are simply not enough and national parks are trying to obtain new funds. We are now testing a system at Poas National Park where visitors can make donations to the park. The entrance fee remains the same seven dollars, but people have the possibility to make voluntary donations to the park in addition to the fee. Contributions will be used to improve the standard of living of park rangers, to provide for better trails and to make sure that this beautiful and unique ecosystem is well taken care of."

The effect of a social reference point is analyzed through providing the subjects with information about a typical previous contribution of others. If a reference point was provided, the following sentence was read:

"We have interviewed tourists from many different countries and one of the most common donations has been 2 / 5 / 10 US dollars."

The monetary reference values used were obtained from a pilot study conducted at the same park right before the main experiment. In the treatments with no mentioned reference amount, the above sentence was simply omitted. 
Finally, the actual request for a contribution differed depending on whether the contribution was to be anonymous or not. In the anonymous case, subjects were asked to go into a private area that was part of our interviewing station and put their contribution, if any, in a sealed envelope and into a small ballot box, making the contribution completely anonymous to the solicitor. ${ }^{3}$ In this case, the following text was read:

"How much are you willing to donate to this fund? Please go to the booth and put the amount of money you would like to donate in the envelope. Remember that donations will be used exclusively to maintain and improve the Poas National Park, as described before. When you are done, please seal the envelope and put it in this box. Do not show it to me, because your donation should be completely anonymous. Please put the envelope in the box even if you do not wish to donate anything."

We provided a locked ballot box in which the contributions were put. This box was actually part of the interviewing station where the subject and the solicitor would sit for the experimental session. In the non-anonymous setting, the following text was read:

"How much are you willing to donate to this fund? Remember that donations will be used exclusively to maintain and improve the Poas National Park, as described before. When you are done reading, please give the envelope and your contribution to me so that I can count and register your donation before sealing the envelope. Please return the envelope even if you do not wish to donate anything."

Thus, in this treatment the subjects were well aware that the solicitor was observing each contribution.

\footnotetext{
${ }^{3}$ In order for us to identify the contributions and link them to the questions in the questionnaire, an ID number was written on the envelope. The subjects were informed about the ID number and the reason for using it. The important point here is that the solicitors were not able to observe the contributions, not even afterwards.
} 
Table 1 summarizes the experimental design for all three treatments. In total 997 subjects participated in the experiment. The different treatments were conducted at the same time, and they were randomly distributed both in terms of time of day and among solicitors. The only exception is that we did not conduct interviews with and without gifts at the same time.

\section{$<<$ Table 1 about here $>>$}

Besides the differences described above, everything else was identical in all interviews and the typical variations of a field experiment (weather, type of tourist, etc) are expected to randomly affect our results.

\section{Results}

Table 2 presents the basic results from the field experiments. As can be observed, in total $52 \%$ of the subjects chose to contribute and the average contribution was $\$ 2.49$ for the whole sample. In total 997 subjects were approached and we raised $\$ 2,775$.

\section{$<<$ Table 2 about here $>>$}

The distribution of the contributions is skewed, with a large fraction of zeros and a few very large contributions; the largest contribution was $\$ 100$. The first histogram in Figure 1 shows the distribution of conditional contributions for the whole experiment. Note that the rightmost bar is contributions larger than $\$ 10$.

\section{$<<$ Figure 1 about here $>>$}

We also present the results from a regression analysis. As argued by Botelho et al. (2005), it is important to correct for possible differences when using subjects who typically have a larger variation in terms of socio-economic characteristics than students have. Another advantage of the regression analysis is that it allows us to handle extreme responses in a systematic way.

The dependent variable, contributions, is censored since it equals zero for a substantial fraction of the subjects. In addition, there are two issues of interest here: whether to contribute anything at all and how much to contribute, given a positive contribution. Since there are good reasons to consider these as two different decisions, a basic Tobit model would be inappropriate. Here we will therefore instead use a simple two-stage model. The decision whether to contribute anything or not is modeled with a standard probit model. The decision concerning how much to contribute, given a 
positive contribution, is modeled with a regression model using only subjects with a positive contribution. ${ }^{4}$ However, the contribution distribution is skewed due to a few outliers. A standard ordinary least squares model would therefore put an inappropriately large weight on the outliers. In order to deal with this problem we apply a robust regression. ${ }^{5}$

The base case in the regression models is the anonymous treatment without reciprocity and no mention of a reference contribution. Table 3 presents the marginal effects for the two estimated models together with the total marginal effect, i.e. including the effects of the probit stage; all marginal effects are calculated at sample means. ${ }^{6}$ The total marginal effect is calculated as

$$
\frac{\partial E\left[C_{i}\right]}{\partial x_{i}}=\frac{\partial P\left[C_{i}>0\right]}{\partial x_{i}} E\left[C_{i} \mid C_{i}>0\right]+\frac{\partial E\left[C_{i} \mid C_{i}>0\right]}{\partial x_{i}} P\left[C_{i}>0\right],
$$

where $E\left[C_{i}\right]$ is the expected contribution of individual $i, P\left[C_{i}>0\right]$ is the probability that individual $i$ contributes anything at all, and $x_{i}$ is a covariate. Both the probit model and the regression models include a constant, solicitor dummy variables, and a few individual socio-economic characteristics. ${ }^{7}$

\section{$<<$ Table 3 about here $>>$}

\footnotetext{
${ }^{4}$ We also estimated a sample selection model allowing for a correlation between the probit and the regression models. However, we could never reject the hypothesis of no sample selection.

${ }^{5}$ We use the rreg command in STATA. First a standard regression is estimated, and observations with a Cook's distance larger than one are excluded. In our case 19 observations are excluded. After that, the model is estimated iteratively: it performs a regression, calculate weights based on absolute residuals, and regresses again using those weights (STATA, 2005). See Rousseeuw and Leroy (1987) for a description of the robust regression model.

${ }^{6}$ For the probit model the marginal effect for dummy variables is for a discrete change of the variable from zero to one.

${ }^{7}$ The individual characteristics included in the regressions are gender and age of the subjects, whether they are members of an environmental organization, whether they saw the volcano, a dummy variable for US subjects, and a dummy variable for European subjects. Among other things, we find that male subjects are more likely to contribute, but that there is no difference in the conditional contribution. One explanation for this could be that four of our five solicitors were females. As shown by Landry et al. (2006), contributions are positively correlated with the physical attractiveness of female solicitors for male contributors. We also find that older subjects are more likely to contribute and that they on average contribute more, possibly indicating that there is a positive relationship between age and non-selfish preferences; cf. List (2004). However, since we cannot accurately control for income, another possible reason is simply that older people have higher income. We also find that members of an environmental organization are more likely to contribute, but on average they do not contribute more. Finally, we tested for differences among subjects from Europe, the US, and South America, without finding any statistically significant differences.
} 
Anonymity

From Table 2 we see that the share of subjects contributing is higher in the nonanonymous treatment, but using the chi-square test of equal proportions contributing we cannot reject the hypothesis of equal proportions $(\mathrm{p}=0.433)$. The average contribution is $25 \%$ higher compared with the anonymous treatment, but using the Wilcoxon-MannWhitney test of equal contribution distributions we cannot reject the hypothesis of equal distributions $(\mathrm{p}=0.166)$. We do find that the average conditional contribution is $19 \%$ higher in the non-anonymous treatment and using the Wilcoxon-Mann-Whitney test we can reject the hypothesis of equal distributions $(\mathrm{p}=0.09)$. The results can be compared to List et al. (2004) who found that the proportion of subjects voting in favor of a proposal of financing a public good is significantly lower in a treatment where subjects are completely anonymous (20\%) compared with a treatment where the solicitor observes the behavior (38\%).

However, if we then look at the results of the regression models we see that anonymity only plays a role in the reciprocity treatment. In the models with interaction effects, the dummy variable for the non-anonymous treatment is insignificant. However, the interaction variable between the non-anonymous and the reciprocity treatments is significant in both the probit model and the robust regression. Thus, in the case of reciprocity, non-anonymity increases the probability of contributing but decreases the conditional contribution. This difference between reciprocity and no-reciprocity treatments is also confirmed using the Wilcoxon-Mann-Whitney test; it is only for the reciprocity treatments that there is a significant difference in contribution distributions between the anonymous and non-anonymous treatments.

\section{Reciprocity}

Comparing the treatments with and without reciprocity in Table 2, we see that the share of subjects contributing a positive amount is 8 percentage points higher in the reciprocity treatment. This is somewhat smaller than in Falk (2005), where participation increases by 17 percentage points when a small gift is included. However, the conditional average contribution is smaller in the treatment with reciprocity. Still, the first effect dominates, resulting in a slightly higher average sample contribution, i.e. the average contribution in the whole sample is a little bit more than 5 percentage points 
higher in the reciprocity treatment. All these effects are significant: Using the Wilcoxon-Mann-Whitney test of equal distributions we can reject the hypothesis of equal distributions both for the conditional sample $(\mathrm{p}=0.040)$ and for the whole sample $(p=0.096)$; and using the chi-square test of equal proportions contributing we can also reject the hypothesis of equal proportions $(p=0.007)$. The total effect of reciprocity is an increase in average contributions by $\$ 0.13$. This can be compared with the cost of the gift of $\$ 1.50$. Thus, not considering any other effects, giving a gift before subjects are asked to contribute is far from profitable. This is consistent with the casual observations that most organizations that raise money in similar ways do not use gifts to invoke reciprocity. ${ }^{8}$ An exception sometimes mentioned is Hare Krishna. According to Cialdini (2001), their strategy of handing over a small gift such as a book or a flower was initially very successful in invoking reciprocity and thus increasing contributions. However, over time this strategy became less efficient when people became aware that this was in fact just a strategy to raise more money. We believe that this points to something fundamentally important that also concerns the results in our experiment, namely that not only the consequences of an action matter, but also the intentions (cf. Dufwenberg and Kirchsteiger, 2004; Rabin, 1993). In our case, a reason for the somewhat small degree of reciprocity may well be that many subjects felt that the intention of giving the gift was to increase contributions.

The regression analysis reveals that giving a small gift to the subject increases the probability that the subject contributes anything at all by around 10 percentage points. At the same time, the average conditional contribution is around $\$ 0.80$ lower when the contribution is anonymous. The net effect is quite small and insignificant. When we interact anonymity with reciprocity, we can see that basically all of the probability effect is obtained in the non-anonymous treatment, and that this effect is more or less completely off-set by a decrease in conditional contribution. Thus, it seems that the effects of reciprocity are much larger in a non-anonymous context, which is also intuitively reasonable.

\section{Conformity}

\footnotetext{
${ }^{8}$ There could of course be other positive effects of giving a small gift, either before or after a contribution. Subjects may feel more attached to the organization and may support it in other instances. It can also result in increased contributions over time.
} 
For reference contributions, we can make a number of comparisons. Compared with not giving any information about other people's contributions, it can be observed from Table 2 that the share of subjects contributing is higher if a $\$ 2$ reference contribution is communicated, and the difference is significant $(\mathrm{p}=0.002)$. However, while the average contribution and the conditional average contribution are lower, it is only the difference in distribution for the latter that is significant $(p=0.001)$. If we then compare the different treatments with a reference contribution, the share of subjects contributing decreases as the reference level increases, although the difference in shares between $\$ 5$ and $\$ 10$ is not significant. At the same time, the average conditional contribution increases, and the difference in the distributions is significant in all cases. To gain additional insights on the differences among the treatments, Figure 1 presents histograms for the conditional contribution for all treatments; the rightmost bar is again contributions greater than $\$ 10$. One clear difference is that the $\$ 2$ reference contribution results in fewer larger contributions. As expected, the most common contribution is $\$ 2$ if a reference point of $\$ 2$ is given. Similarly, $\$ 5$ is the most common if a $\$ 5$ reference is given, and $\$ 10$ is the most common if a $\$ 10$ reference is given.

The results from the regression analysis largely confirm the results from the nonparametric analysis. The likelihood of contributing anything at all is significantly higher in the $\$ 2$ reference contribution treatment compared with all other treatments. At the same time, the average conditional contribution decreases by $\$ 1.10$ compared to the treatment without a reference contribution; these two opposite effects results in an insignificant total effect. Since the total effect is insignificant, some of those who would have contributed anyway ended up contributing less than without the reference contribution. This may be because subjects without any information tended to believe that a typical contribution is higher than $\$ 2$, which is correct since according to Table 1 others contributed on average around $\$ 5$ in the no treatment case. This new knowledge creates two effects. On the one hand, when faced with a typical average contribution of only $\$ 2$, those who would have contributed anyway responded by on average lowering their contributions. On the other hand, the other subjects realized that it is rather cheap to adhere to the typical practice and hence agreed to a positive contribution. In this way the result is an increased participation but lower conditional contributions. 
The $\$ 10$ reference contribution results in an average conditional contribution that is around $\$ 0.70$ higher compared with not giving any reference information. The total effect is almost $\$ 0.50$; thus, presenting a $\$ 10$ reference contribution increases average contributions by 50 cents compared with not giving any information at all. ${ }^{9}$ This difference is somewhat larger than what the simple comparison between average contributions revealed in Table 2 .

In order to compare our results with Shang and Croson (2006), we need to focus on average conditional contributions since, by the nature of their experiment, they were able to look only at positive contributions. If we take the average conditional contribution for the no reference treatment (\$6) as given, providing a reference contribution of $\$ 10$ results in an increase of almost $12 \%$. This can be directly compared with Shang and Croson (2006) who also found a 12\% increase in contributions for their highest reference contribution. However, they found increasing conditional contributions for reference contributions that were below the average contribution in the baseline case as well, whereas we find negative or insignificant effects for our two such reference levels (i.e. the $\$ 2$ and $\$ 5$ reference treatments, respectively).

It is also interesting to test whether the social reference contribution has a stronger effect if it is expressed in the same currency as the subjects are used to. The reference contributions were expressed solely in US dollars, but the subjects were free to contribute in any currency, and some subjects actually contributed in several currencies; $51 \%$, contributed only in dollars and $45 \%$ contributed only in colones. ${ }^{10}$ To test if the behavior differed between these two groups we estimate an additional robust regression for the conditional contribution. This regression includes a dummy variable equal to one if the contribution was made only in dollars. This dummy variable is also interacted with the reference contribution dummy variables. The results of the regression are reported in the last two columns of Table 3. We find that people who contributed in dollars on average contributed more. ${ }^{11}$ More importantly, we find that it is mostly these subjects who "react" to the $\$ 10$ reference contribution. Thus, our result that a $\$ 10$

\footnotetext{
${ }^{9}$ The effect compared with for example a $\$ 2$ reference contribution is of course even larger.

${ }^{10} \$ 1$ = 500 Costa Rican Colones. Note that only international tourists participated in the experiment. $57 \%$ of those who contributed only in dollars and $53 \%$ of those who contributed only in colones were Americans. There is no significant difference with respect to gender or age between these two groups. Finally, those who only contributed in dollars, contributed on average $\$ 1.10$ more than the other subjects. ${ }^{11} \mathrm{We}$ attempted to correct this result by nationality, but the effect was not significant. The US dollar is the standard currency for tourists in Costa Rica. See previous footnote.
} 
reference contribution results in a large average contribution is driven by this subsample. We do not find any significant interaction effect for the other reference levels. A possible explanation is that a subject who contributes in a currency other than dollars has to calculate how much the reference contribution is worth in that currency. A subject will therefore face the choice of whether it is worthwhile undertaking this calculation exercise. Suppose that the subject has a very rough perception of the order of magnitude of the reference amount. If the reference level is a low amount, the subject knows that others have contributed a rather small amount. He may then be tempted to calculate exactly how much others have contributed, since such information would not be potentially damaging for his self-image. If, on the other hand, others have contributed a lot, such as $\$ 10$, an exact calculation of how much this corresponds to would make the reference level more salient, which in turn might be damaging for the subject's ego since it would likely mean that he himself is willing to contribute less than others. Alternatively, saving his ego would be expensive to him.

\section{Conclusions}

Using a natural field experiment, we have quantified the importance of anonymity, reciprocity, and conformity through the provision of social reference levels in order to explain voluntary contributions to a national park in Costa Rica. All total effects of the various treatments have the expected signs.

We found an effect of anonymity, even if it is not significant. Contributions in front of the solicitor are on average $25 \%$ larger than contributions made in private. We also found that the reciprocity treatment induces more people to contribute, while decreasing the average conditional contribution. Something similar applies for the comparison between providing no reference information and providing a reference of \$2. These two treatments seem to "force" contributions from subjects who would not otherwise contribute, but in line with their baseline preferences, they tend to contribute less than others. The net effect of providing a reference amount of a magnitude similar to the mean contribution in the base case (with no reference contribution) has virtually no effect on the conditional contribution. Providing a smaller or larger reference amount decreases and increases the size of the contribution, respectively. The overall effects are

perhaps smaller than expected, compared with findings from laboratory experiments. A 
possible explanation is that decisions in the laboratory to a larger extent than real world decisions tend to influence people in asking themselves, "What type of person am I?" Consequently, subjects may be affected more by different treatments in a lab environment. Although it is an important step to move outside the lab, the findings can of course not be generalized to all possible real-life situations. For example, the importance of being perceived by others as generous, and perhaps committed to a good cause, most likely depends on who is observing one's behavior. The solicitor is presumably not that important for the subjects, and it is only one person. Hence, we expect anonymity to be much more important in other contexts. In our setting, the effects of the various treatments are small. This suggests that the self-image, or identity, as an honorable person, irrespective of other people's opinions, is an important explanation of contribution behavior. As expressed by Adam Smith almost 250 year ago (Smith, 1759, p. 170):

\footnotetext{
"Nature, accordingly, has endowed him, not only with a desire of being approved of, but with a desire of being what ought to be approved of; or of being what he himself approves of in other men. The first desire could only have made him wish to appear to be fit for society. The second was necessary in order to render him anxious to be really fit. The first could only have prompted him to the affectation of virtue, and to the concealment of vice. The second was necessary in order to inspire him with the real love of virtue, and with the real abhorrence of vice. In every well-formed mind this second desire seems to be the strongest of the two."
}

One may finally suggest that the results have practical implications for charitable organizations that would like to maximize revenues. However, we believe that one should be cautious in this respect. First, most quantitative effects are relatively small, and sometimes not significant. Second, and more important, some of the results may change in the long run, in the same way as it appeared to have become unprofitable for Hare Krishna to hand over gifts to potential givers. For example, if it becomes well known that a certain organization tends to ask people to contribute money in a nonanonymous way, then people might avoid these organizations. Similarly, people may feel uneasy if they are told that others tend to give a certain specified amount. Consequently, the positive effects of reducing or eliminating anonymity and providing potential donors with the information that many others have contributed a lot may be reduced over time and perhaps even become negative. The advice that we feel most 
confident about is that it in most cases appears unprofitable for charitable organizations to hand out costly gifts to potential donors. ${ }^{12}$ Thus, in this respect the only advice we can give is to go on with the current practice. Overall, this study has not produced any clear evidence that the current practice of charitable organizations is inefficient. If anything, it seems rather that the charitable market works.

\footnotetext{
${ }^{12}$ Still, there are of course limits to the extent to which this result can be generalized. For example, we do not suggest that it would necessarily be a bad idea for a charity organization to pay a dinner for Bill Gates.
} 


\section{References}

Akerlof, G. and R. Kranton (2000). Economics and identity, Quarterly Journal of Economics, 115(3), 715-53.

Andreoni, J. (2004). Philanthropy, in Handbook of Giving, Reciprocity, and Altruism, L.A. Gerard-Varet, S.C, Kolm, and J.M. Ythier (Eds).

Andreoni, J. and J.K. Scholz (1998): An econometric analysis of charitable giving with interdependent preferences, Economic Inquiry, 36(3): 410-428.

Benabou, R. and J. Tirole (2002), Self-confidence and personal motivation, Quarterly Journal 117, 871-914.

Benabou, R. and J. Tirole (2006), Incentives and Prosocial Behavior, American Economic Review, forthcoming.

Bernheim, D. (1994). A theory of conformity, Journal of Political Economy 102, 841877.

Bohnet, I. and R. Zeckhauser (2004) Social Comparisons in Ultimatum Bargaining, Scandinavian Journal of Economics 106, 495-510.

Botelho, A., G. W. Harrison, M. A. Hirsch, and E. Elisabet Rutström (2005) Bargaining Behavior, Demographics and Nationality: What Can the Experimental Evidence Show? in J. Carpenter, G.W. Harrison and J.A. List (eds.), Field Experiments in Economics, Greenwich, CT: JAI Press, Research in Experimental Economics, Volume 10, 337-372.

Brennan, G and P. Pettit (2004) The Economy of Esteem. Oxford: Oxford University Press.

Camerer, C. F. (2003), Behavioral Game Theory: Experiments on Strategic Interaction, Princeton: Princeton University Press, New Jersey.

Cialdini, R. (2001) Influence. Science and Practice. Boston: Allyn and Bacon.

Dufwenberg, M. and G. Kirchsteiger (2004). A Theory of Sequential Reciprocity. Games and Economic Behavior 47, 268-298.

Falk, A. (2005) Charitable Giving as a Gift Exchange: Evidence from a Field Experiment, IZA Discussion Paper No. 1148, University of Bonn.

Falk, A. and U. Fischbacher (2006). A Theory of Reciprocity, Games and Economic Behavior 54, 293-315. 
Fehr, E. and Gächter, S. 2000. Fairness and retaliation: The economics of reciprocity. Journal of Economic Perspectives. 14, 159-181.

Fischbacher, U., S. Gächter and E. Fehr (2001) Are People Conditionally Cooperative? Evidence from a Public Good Experiment, Economics Letters 71, 397-404.

Frey, B. and S. Meier (2004) Social Comparisons and Pro-Social Behavior: Testing “Conditional Cooperation" in a Field Experiment, American Economic Review 94, 1717-1722.

Harrison, G. and J. List (2004) Field Experiments, Journal of Economic Literature $42,10091055$.

Heldt, T. (2005) Conditional cooperation in the field: cross-country skiers' behavior in Sweden, Working Paper Department of Economics and Society, Dalarna University.

Hoffman, E., K. McCabe and V. Smith (1996) On Expectations and Monetary Stakes in Ultimatum Games, International Journal of Game Theory 25, 289-301.

Karlan, D. and J. List (2006) Does Price Matter in Charitable Giving? Evidence from a Large-Scale Natural Field Experiment, Unpublished manuscript.

Kuran, T. (1995) Private Truths, Public Lies: The Social Consequences of Preference Falsification Cambridge, Mass.: Harvard University Press.

Landry, C., Lange A, List, J., Price, M. and N. Rupp (2006) Toward an understanding of the economics of charity: evidence from a field experiment, Quarterly Journal of Economics 121, 747-782.

Laury, S.K., Walker, J.M., Williams, A.W. (1995) Anonymity and the Voluntary Provision of Public Goods, Journal of Economic Behavior and Organization 27, 365-380.

Ledyard, J. O. (1995). Public Goods: A Survey of Experimental Research, Handbook of Experimental Economics. Eds.: J. Kagel and A. E. Roth. Princeton: Princeton University Press.

Levitt, S. and List, J. (2006). What do laboratory experiments tell us about the real world? University of Chicago, working paper.

List, J. (2004) Young, Selfish and Male: Field Evidence of Social Preferences, Economic Journal 114, 121-149. 
List, J., R. Berrens, A. Bohara and J. Kerkvilet (2004) Examining the Role of Social Isolation on Stated Preferences, American Economic Review 94, 741-752.

Masclet, D., Noussair, C., Tucker, S. and Villeval, M.-C. (2004) Monetary and NonMonetary Punishment in the Voluntary Contribution Mechanism, American Economic Review 93, 366-380.

Martin, R. and J. Randal (2005) Voluntary contributions to a public good: a natural field experiment. Unpublished manuscript, Victoria University, New Zealand.

Potters, J., M. Sefton and L. Vesterlund (2005) After you -endogenous sequencing in voluntary contribution games. Journal of Public Economics 89, 1399-1419.

Rabin, M. (1993). Incorporating fairness into game theory. American Economic Review $83,1281-1302$.

Rege, M. and K. Telle (2004) The Impact of Social Approval and Framing on Cooperation in Public Good Situations, Journal of Public Economics 88, 16251644.

Roth, A. (1995) Bargaining Experiments, in Roth, A. and J. Kagel (eds.) Handbook of Experimental Economics. Princeton: Princeton University Press.

Rousseeuw, P.J. and A.M. Leroy (1987) Robust Regression and Outlier Detection. Wiley: New York.

Shang, J. and R. Croson (2006) Field Experiments in Charitable Contribution: The Impact of Social Influence on the Voluntary Provision of Public Goods. Unpublished manuscript.

Smith, A. (1759) The Theory of Moral Sentiments.

Amherst, New York: Prometheus Books.

Soetevent, A.R. (2005) Anonymity in Giving in a Natural Context: An Economic Field Experiment in Thirty Churches. Journal of Public Economics 89: 2301-2323.

STATA (2005) STATA Base Reference Manual, Stata Press: College Station, TX.

Vesterlund, L. (2006) Why Do People Give? Walter W. Powell and Richard S. Steinberg (Eds.), The Nonprofit Sector: A Research Handbook, $2^{\text {nd }}$ Edition, Yale University Press, 2006. 
Table 1. Experimental design for all treatment combinations.

\begin{tabular}{lccccc}
\hline & \multicolumn{2}{c}{ No reciprocity } & \multicolumn{2}{c}{ Reciprocity } & Total \\
\cline { 2 - 4 } & Anonymous & Non-anonymous & Anonymous & Non-anonymous \\
\hline No reference donation & 62 observations & 63 observations & 62 observations & 63 observations & 250 \\
Reference donation: $\$ 2$ & 61 observations & 63 observations & 62 observations & 63 observations & 249 \\
Reference donation: $\$ 5$ & 62 observations & 62 observations & 62 observations & 63 observations & 249 \\
Reference donation: $\$ 10$ & 62 observations & 62 observations & 62 observations & 63 observations & 249 \\
\hline Total & 247 observations & 250 observations & 248 observations & 252 observations & 997 \\
\hline
\end{tabular}

Table 2. Descriptive field-experimental results.

\begin{tabular}{lcccc}
\hline & $\begin{array}{c}\text { Observa- } \\
\text { tions }\end{array}$ & $\begin{array}{c}\text { Share pos. } \\
\text { contribution }\end{array}$ & $\begin{array}{c}\text { Conditional average } \\
\text { contribution (std) }\end{array}$ & $\begin{array}{c}\text { Sample average } \\
\text { contribution (std) }\end{array}$ \\
\hline No reciprocity & 497 & 0.48 & $5.09(5.74)$ & $2.43(4.70)$ \\
Reciprocity & 500 & 0.56 & $4.56(6.97)$ & $2.56(5.69)$ \\
\hline Anonymous & 495 & 0.51 & $4.36(4.79)$ & $2.21(4.05)$ \\
Non-anonymous & 502 & 0.53 & $5.21(7.65)$ & $2.77(6.15)$ \\
\hdashline No Reference & 250 & 0.47 & $6.00(10.49)$ & $2.20(3.58)$ \\
Reference: $\$ 2$ & 249 & 0.61 & $3.61(3.99)$ & $1.98(2.82)$ \\
Reference: $\$ 5$ & 249 & 0.50 & $3.95(2.84)$ & $2.95(5.20)$ \\
Reference: $\$ 10$ & 249 & 0.49 & $5.97(6.06)$ & $2.49(5.22)$ \\
\hline Total & 997 & 0.52 & $4.80(6.43)$ & - \\
\hline
\end{tabular}


Figure 1. Distribution of contributions for reference contribution treatments.

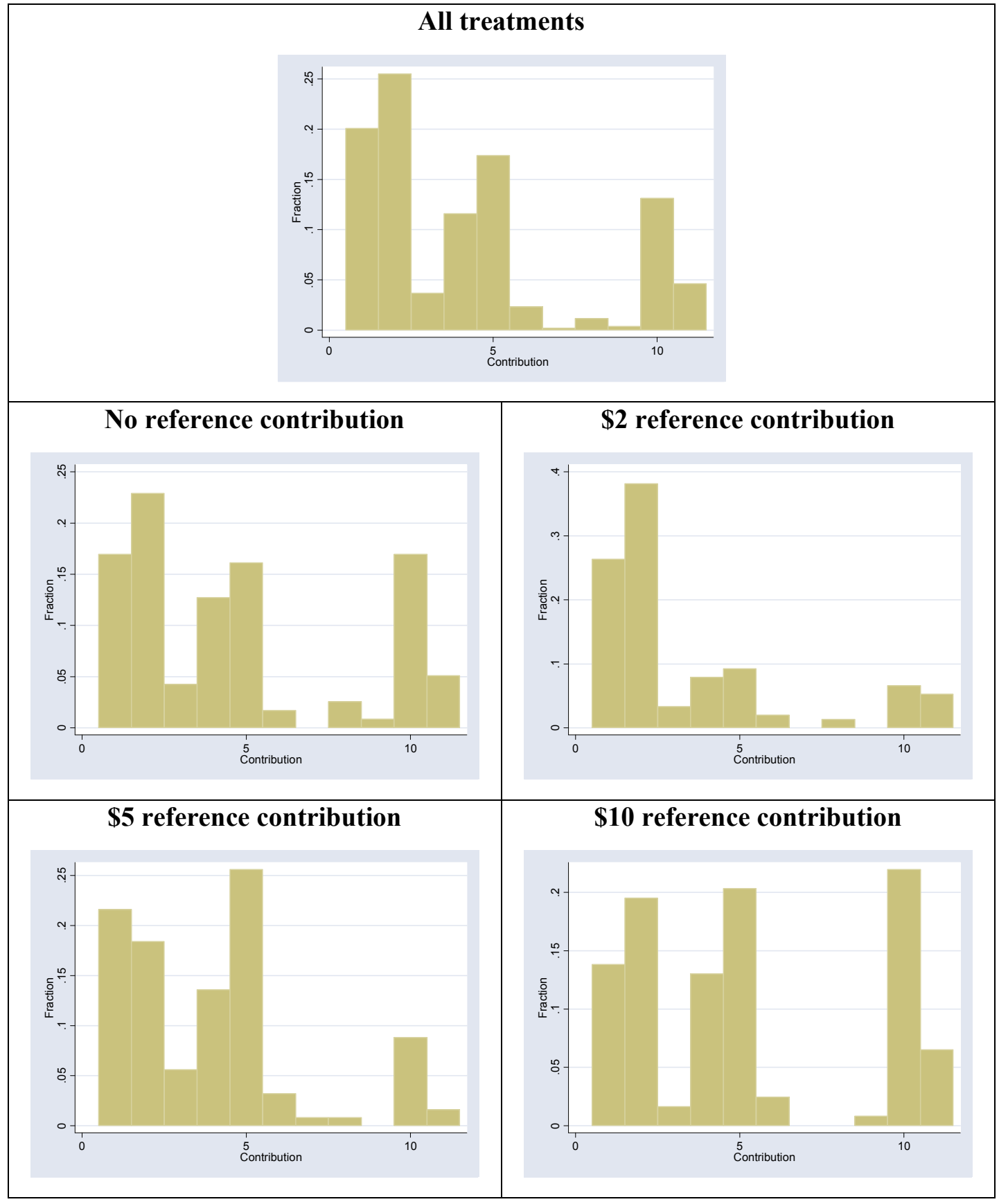


Table 3. Regression analysis of contributions to the national park. The coefficients reflect marginal effects evaluated at sample means. All models include an intercept, solicitor dummy variables and subject characteristics variables. P-values in parentheses.

\begin{tabular}{|c|c|c|c|c|c|c|c|c|}
\hline & \multicolumn{3}{|c|}{$\begin{array}{l}\text { 2-stage robust regression } \\
\text { (main effects) }\end{array}$} & \multicolumn{3}{|c|}{$\begin{array}{l}\text { 2-stage robust regression } \\
\text { (with interaction effects for } \\
\text { anonymity and reciprocity) }\end{array}$} & \multirow{2}{*}{$\begin{array}{l}\text { Robust } \\
\text { regression of } \\
\text { conditional } \\
\text { contribution } \\
\text { (main } \\
\text { effects) }\end{array}$} & \multirow{2}{*}{$\begin{array}{c}\text { Robust } \\
\text { regression of } \\
\text { conditional } \\
\text { contribution } \\
\text { (interaction } \\
\text { effects) }\end{array}$} \\
\hline & $\begin{array}{c}\text { Probit } \\
\mathrm{P}(\text { Contrib. }>0)\end{array}$ & $\begin{array}{l}\text { Robust regression } \\
\text { of conditional } \\
\text { contribution }\end{array}$ & $\begin{array}{l}\text { Total } \\
\text { effect }\end{array}$ & $\begin{array}{c}\text { Probit } \\
\mathrm{P}(\text { Contrib. }>0)\end{array}$ & $\begin{array}{c}\text { Robust regression } \\
\text { of conditional } \\
\text { contribution }\end{array}$ & $\begin{array}{l}\text { Total } \\
\text { effect }\end{array}$ & & \\
\hline Non-anonymous & 0.023 & 0.232 & 0.230 & 0.018 & -0.127 & 0.022 & 0.281 & 0.013 \\
\hline treatment & $(0.480)$ & $(0.356)$ & $(0.256)$ & $(0.687)$ & $(0.736)$ & $(0.940)$ & $(0.238)$ & $(0.970)$ \\
\hline Reciprocity treatment & $\begin{array}{c}0.100 \\
(0.003)\end{array}$ & $\begin{array}{l}-0.484 \\
(0.070)\end{array}$ & $\begin{array}{c}0.228 \\
(0.283)\end{array}$ & & & & $\begin{array}{l}-0.496 \\
(0.050)\end{array}$ & \\
\hline Reciprocity treatment * & & & & 0.005 & 0.658 & 0.367 & & 0.474 \\
\hline Anonymous treatment & & & & $(0.935)$ & $(0.201)$ & $(0.369)$ & & $(0.326)$ \\
\hline Reciprocity treatment $*$ & & & & 0.089 & -0.810 & 0.007 & & -0.726 \\
\hline Non-anonym. treatment & & & & $(0.057)$ & $(0.036)$ & $(0.982)$ & & $(0.045)$ \\
\hline Treatment with \$2 & 0.152 & -1.123 & 0.147 & 0.148 & -1.154 & 0.110 & -1.174 & -1.186 \\
\hline reference contribution & $(0.001)$ & $(0.002)$ & $(0.600)$ & $(0.001)$ & $(0.001)$ & $(0.697)$ & $(0.009)$ & $(0.009)$ \\
\hline Treatment with $\$ 5$ & 0.049 & 0.035 & 0.254 & 0.046 & -0.006 & 0.216 & -0.116 & -0.137 \\
\hline reference contribution & $(0.280)$ & $(0.924)$ & $(0.384)$ & $(0.314)$ & $(0.986)$ & $(0.461)$ & $(0.810)$ & $(0.780)$ \\
\hline Treatment with $\$ 10$ & 0.028 & 0.711 & 0.503 & 0.018 & 0.664 & 0.458 & -0.566 & -0.604 \\
\hline Made contribution in & & & & & & & 0.578 & 0.557 \\
\hline dollars only & & & & & & & $(0.249)$ & $(0.271)$ \\
\hline Contribution in dollar * & & & & & & & 0.049 & 0.056 \\
\hline$\$ 2$ reference contribution & & & & & & & $(0.941)$ & $(0.933)$ \\
\hline Contribution in dollar * & & & & & & & 0.205 & 0.233 \\
\hline$\$ 5$ reference contribution & & & & & & & $(0.769)$ & $(0.740)$ \\
\hline \multicolumn{9}{|l|}{ Contribution in dollar * } \\
\hline $\begin{array}{l}\$ 10 \text { reference } \\
\text { contribution }\end{array}$ & & & & & & & $\begin{array}{l}2.379 \\
(0.001)\end{array}$ & $\begin{array}{c}2.399 \\
(0.001)\end{array}$ \\
\hline $\begin{array}{l}\text { Solicitor dummy } \\
\text { variables }\end{array}$ & Included & Included & Included & Included & Included & Included & Included & Included \\
\hline $\begin{array}{l}\text { Subject characteristics } \\
\text { variables }\end{array}$ & Included & Included & Included & Included & Included & Included & Included & Included \\
\hline
\end{tabular}

